\title{
ISQUEMIA MESENTÉRICA POR EMBOLIA NA FIBRILAÇ̃̃O ATRIAL
}
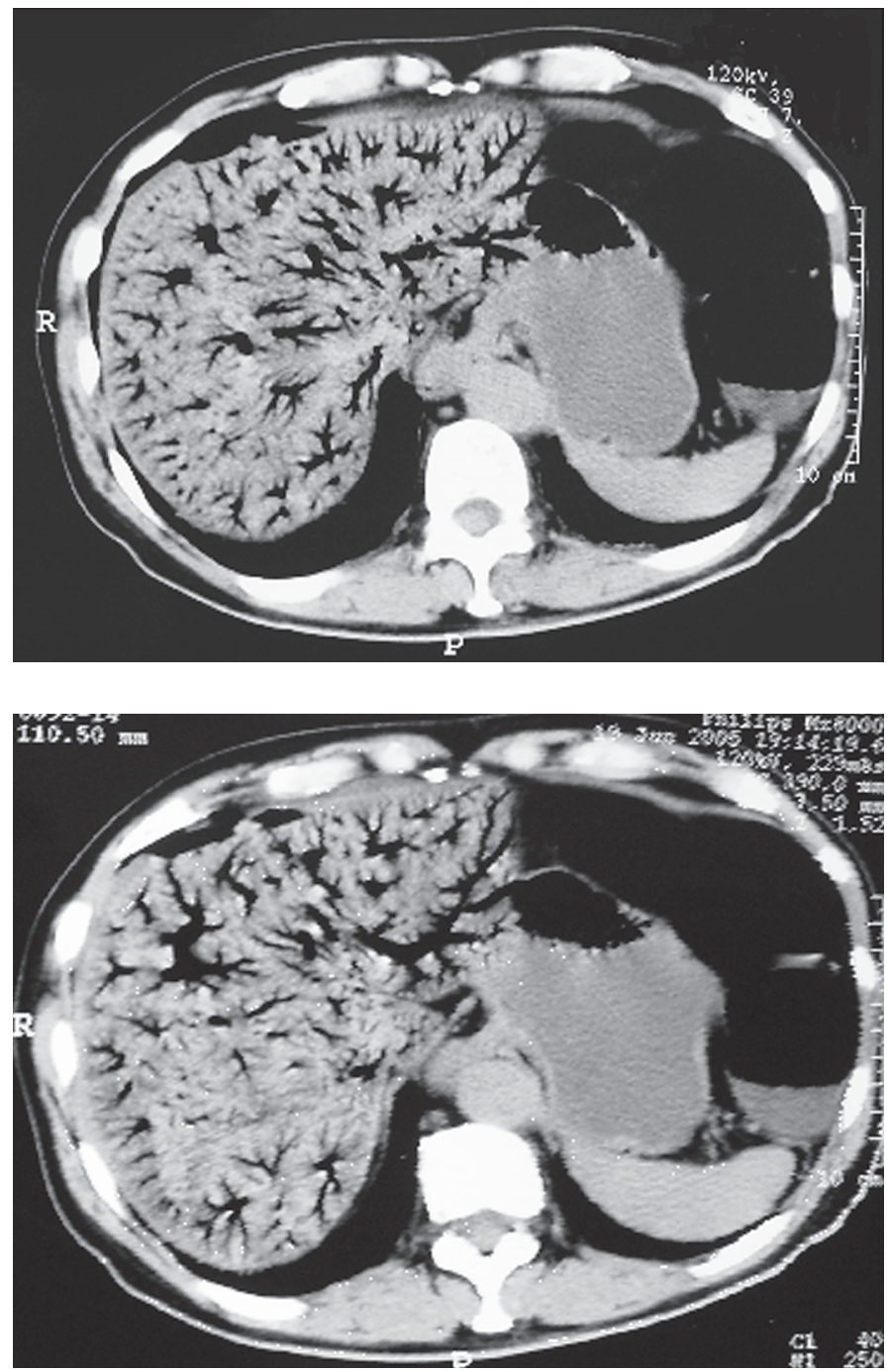

Tomografia computadorizada (TC) de abdome de um paciente do sexo masculino, 63 anos, que procurou o hospital por dor abdominal, náuseas, vômitos e hematoquezia. Como antecedentes, havia realizado uma gastrectomia a Billroth Il há cinco anos e havia sido diagnosticado fibrilação atrial há um mês, porém não foi realizada anticoagulação devido à história de hematoquezia. A TC de abdome revelou pneumatose intestinal difusa com ar no sistema porta e intra-hepático. Foi realizada, então, ressecção do intestino delgado desde o ângulo de Treitz e colectomia total. A vesícula biliar também estava isquêmica e foi ressecada. O paciente foi então transferido à Unidade de Terapia Intensiva (UTI), onde permaneceu durante um mês, evoluindo a óbito por choque séptico de origem pulmonar.

Camila Paiva de Vasconcelos, Bem-Hur ferraz Neto, luis Edmundo Pinto da Fonseca, Ruy Guilherme Rodrigues Cal Trabalho realizado no Hospital Israelita Albert Einstein, São Paulo, SP 